\title{
Publicidad, diversidad fenotípica y dinamización intercultural en Cataluña en tiempos de crisis y cambios
}

\author{
Advertising, phenotypic diversity and intercultural dynamization \\ in Catalonia in times of crisis and change \\ Publicidade, diversidade fenotípica e dinamização intercultural na \\ Catalunha em tempos de crise e mudanças
}

Nicolás Lorite García, Universitat Autònoma de Barcelona, Barcelona, España (nicolas.lorite@uab.cat)

\begin{abstract}
RESUMEN | Este artículo busca examinar el posicionamiento identitario cultural de la publicidad en los tiempos de crisis económica en Cataluña, coincidentes con el cambio nacionalista hacia la independencia de España en el año 2014. Tras analizar una muestra de 441 spots de TV3, la cadena de mayor audiencia en Cataluña, se constata que la interpretación de los personajes recae casi totalmente en el fenotipo blanco-caucásico. Por lo tanto, el discurso publicitario no es representativo de la diversidad cultural de la sociedad catalana actual. Excluye a los "otros" venidos de Latinoamérica, África o Asia, y se posiciona del lado del "nosotros" blancocaucásico y lo "nuestro". No fomenta el lenguaje inclusivo que recomiendan los organismos reguladores de los contenidos mediáticos, como la Mesa por la Diversidad en el Audiovisual del Consejo del Audiovisual de Cataluña (2013), para promover la dinamización intercultural y evitar la xenofobia.
\end{abstract}

PALABRAS CLAVE: publicidad; televisión; representación fenotípica; crisis económica; nacionalismo; diversidad cultural; publicidad inclusiva; dinamización intercultural; Cataluña. 
ABSTRACT / This article aims to examine the cultural identity positioning of advertising in times of economic crisis in Catalonia, coinciding with the nationalist shift towards the independence from Spain in the year 2014. After analysing a sample of 441 spots from a major Catalan public broadcasting channel (TV3) in Catalonia, we can see that the characters portrayed fall almost entirely in the white-Caucasian phenotype. Therefore, the advertising discourse is not representative of the diversity of Catalan society today, as it excludes "others" from Latin America, Africa, or Asia, and positions itself on the side of the white-Caucausian "us" and "ours". It does not promote the inclusive language recommended by media regulatory bodies, such as the Bureau for Diversity in Audiovisual Of the Catalan Audiovisual Council (2013), to promote intercultural dynamization and avoid xenophobia.

KEYWORDS: advertising; television; phenotypic representation; economic crisis; nationalism; cultural diversity; inclusive advertising; intercultural dynamization; Catalonia.

RESUMO | Este artigo busca examinar o posicionamento identitário cultural da publicidade em tempos de crise econômica na Catalunha, coincidindo com a mudança nacionalista para a independência da Espanha no ano de 2014. Depois de analisar uma amostra de 441 spots da TV3, cadeia de maior audiência na Catalunha, observa-se que a interpretação das personagens recai quase inteiramente no fenótipo brancocaucasiano. Portanto, o discurso publicitário não é representativo da diversidade cultural da sociedade catalã atual. Exclui os "outros" provenientes da América Latina, da África ou da Ásia e se posiciona ao lado de "nós" branco-caucasiano e do "nosso". Não promove a linguagem inclusiva recomendada pelos organismos que regulam os conteúdos midiáticos como a Mesa pela Diversidade no Audiovisual do Conselho Audiovisual da Catalunha (2013), para promover a dinamização intercultural e evitar a xenofobia.

PALAVRAS-CHAVE: publicidade; televisão; representação fenotípica; crise econômica; nacionalismo; diversidade cultural; publicidade inclusiva; Catalunha. 


\section{INTRODUCCIÓN}

Este artículo busca analizar cuál es la representación de la diversidad fenotípica en la publicidad televisiva en el momento álgido de la crisis económica mundial del año 2014, y en una región geoestratégica clave del Mediterráneo y de Europa como lo es Cataluña. Allí, en ese período, se gestaba un cambio político nacionalista importante, propiciado por la población autóctona blanco-caucásica, denominado procés o proceso hacia la independencia de Cataluña de España, pautado desde una hoja de ruta para llegar a una república propia en una fecha determinada, prevista inicialmente para septiembre-octubre del 2017, pero sin fecha específica actualmente.

En este complejo contexto político-económico, transitorio pero determinante a nivel sociocultural, conviene testear la función social de la publicidad desde la construcción de culturas e identidades que apunta Benavides (1995 y 1997), y desde el acompañamiento del discurso publicitario a las élites del poder que aborda Van Dick (1993 y 1997).

Específicamente, se pretende detectar si un elemento tan sumamente clave del discurso visual publicitario como es el fenotipo de los protagonistas posiciona el mensaje publicitario del lado de las identidades blanco-caucásicas que detentan las élites del poder económico y los dirigentes nacionalistas que propugnan la independencia de Cataluña, o se decanta por una representación plural acorde con la diversidad sociocultural de Cataluña. Esta diversidad fue gestada durante el largo periodo previo de bonanza económica y de fomento de propuestas mediáticas inclusivas dinamizadoras de la interculturalidad en Cataluña, recomendadas desde organismos reguladores de los contenidos mediáticos como la Mesa por la Diversidad en el Audiovisual del Consejo del Audiovisual de Cataluña (2013). Son, por tanto, unos tiempos de crisis y cambios desde los que se toman estas referencias cuantitativas y cualitativas con el fin de hacer un seguimiento comparativo en nuevos periodos económicos y políticos para evaluar la eficacia de las recomendaciones sobre publicidad inclusiva propuestas por dicho organismo regulador y aceptadas por la producción y realización publicitaria.

Una de las maneras positivistas de constatar la contribución de la publicidad a posicionarse hacia un determinado modelo identitario es la de codificar los fenotipos de los/las protagonistas de una muestra no sesgada de spots televisivos, difundidos por TV3, cadena catalana de titularidad pública y de mayor audiencia e impacto social en Cataluña, durante el año 2014. A partir de allí, se comprobará si sus rasgos fisiológicos y morfológicos, así como sus interpretaciones con sus respectivos roles (principal, secundario o incidental) e interconexiones (estructurales o coyunturales, inclusivas o excluyentes) con otros personajes 
coinciden con la diversidad plural catalana de esos momentos y sus relaciones interculturales inclusivas, o se decanta únicamente hacia las identidades blancocaucásicas que propugnan las élites económicas multinacionales y detentan las élites nacionalistas en el poder político catalán.

Es un proceso investigador consistente en abordar la función inclusiva intercultural o excluyente monocultural de los mensajes publicitarios televisivos, partiendo de propuestas como las que postulan desde los estudios culturales Curran, Morley y Walkerdine (1996), los interrogantes que se plantea Hall sobre "iquién necesita la identidad?” (Hall \& Gay de, 1996, p. 13), desde las culturas híbridas que aborda García Canclini (1989) y desde la globalización de la identidad en la era de la información que propugna Castells (2001).

Fenómenos como el aquí planteado se abordan desde una metodología cualicuantitativa, multimodal, para extraer conclusiones no solo desde el análisis de contenido de los spots, sino también desde los potenciales efectos dinamizadores interculturales de los mensajes publicitarios en los consumidores de diferentes identidades. Son resultados que van destinados a fomentar el debate sobre publicidad inclusiva, desde los modelos de investigación-acción e investigación audiovisual aplicada, articulados desde la academia en colaboración con las organizaciones, instituciones y empresas del sector (Lorite, Grau Rebollo, \& Lacerda, 2018). Es una investigación-acción porque se realiza conjuntamente entre la Mesa por la Diversidad en el Audiovisual del Consejo del Audiovisual de Cataluña y el MIGRACOM (Observatorio y Grupo de Investigación de Migración y Comunicación) de la Universidad Autónoma de Barcelona, y participan otras universidades catalanas (Universidad de Barcelona y Universidad de Vic) y organizaciones como SOS Racismo y Colegio de Publicitarios y Relaciones Públicas de Cataluña. Asimismo, se vincula a las agencias y productoras audiovisuales publicitarias y organizaciones de anunciantes, como la Asociación de Empresarios de la Publicidad, con el objetivo principal de implicar a todos ellos en la normalización del lenguaje inclusivo dinamizador de la interculturalidad. Es también una investigación audiovisual aplicada, porque se propone la alternativa inclusiva desde las mismas prácticas audiovisuales que realizan los futuros publicitarios en la universidad.

\section{MARCO TEÓRICO}

\section{Contextualización sociomediática}

El año 2014 coincide con un momento álgido de la crisis económica y financiera mundial. Ello comporta en Cataluña la paralización de los flujos migratorios internacionales (Domingo, 2019) e incluso una importante migración de retorno a los países de origen (Parella \& Petroff, 2014). Se constatan altas tasas de desempleo y 
el poco trabajo existente tiende a ser ocupado por un sector de la población autóctona, blanco-caucásico, que antes de la crisis rechazaba estos puestos de trabajo y los salarios que los acompañaban por considerarse preparada para desempeñar un rol profesional y estatus social más alto. Estos puestos de trabajo eran ocupados antes de la crisis por la inmigración latinoamericana y africana (Centre d'Estudis Demogràfics, 2019) e incluso la europea proveniente de países como Rumanía (Pajares, 2006). La precariedad fortalece las actitudes proteccionistas y defensivas de lo "nuestro" a la vez que las del "nosotros" de "aquí", frente a los "otros" de "fuera", migrantes extranjeros de otras identidades. El "nosotros" comporta, por lo tanto, la agrupación en torno a un fenotipo propio, blanco-caucásico, diferente a los rasgos fisiológicos y morfológicos que detentan los "otros". Es una agrupación identitaria que más que construirse por similitud con los "míos" se forma a partir de las diferencias con los "otros", según recogen Castelló (2008) y Rodrigo Alsina (1999). Es lo que desde la Teoría de la Identificación Social de Tajfel (1971) y Turner, Brown y Tajfel (1979) considera como ese entendimiento con los "nuestros" para competir con los "otros" y llegar, incluso, a discriminarlos (Abdelal, Yoshiko, Alastair, \& Rose, 2009).

El año 2014 también coincide con el inicio de un cambio importante de signo nacionalista en Cataluña. Emerge el procés, denominación catalana del proceso hacia la independencia de Cataluña del Estado español, ajustado a los plazos de una hoja de ruta con fecha de finalización prevista para septiembre-octubre del año 2017 con la fundación de una república catalana. Este proceso no llegó a fraguarse y quedó en "naufragio" (García, 2018), pero a pesar de ello sigue siendo defendido por un sector importante de la población catalana y continúa siendo uno de los problemas políticos principales de la política española actual.

El procés lo encabeza un sector de la población autóctona, blanco-caucásica, que reivindica un país con una sola lengua oficial, el catalán (actualmente se da la cooficialidad con el castellano), con unas fronteras que le separarían de Francia y España (de las regiones limítrofes Aragón y Valencia), con sus tradiciones folklóricas (els castells o castillos humanos y la sardana o baile en círculo como más representativos), y una serie de valores identitarios y costumbres. Estos últimos son recuperados de episodios históricos, como el de la Guerra de Sucesión de 1714, reivindicados por la burguesía catalana en diferentes momentos del Modernismo, a finales del siglo XIX y principios del XX, y defendidos por partidos históricos como Esquerra Republicana de Catalunya (ERC) ya desde la II República Española del 1931. Es un movimiento identitario trasversal que, como todos los nacionalismos, es excluyente (aunque se considere representativo de todo el "pueblo" catalán) de las otras identidades culturales, lingüísticas, musicales y demás tradicionales y costumbres propias de las migraciones internacionales, 
venidas de América Latina, África y Asia, e, incluso, de las migraciones internas, llegadas de otros lugares de España como Andalucía, con propuestas musicales como el cante y baile flamenco

Para verificar la identidad de los protagonistas de los mensajes publicitarios y cotejar si dicha representación mediática se posiciona hacia la homogeneidad identitaria blanco-caucásica, propia de las élites económicas dominantes de los tiempos de crisis económica y cambios nacionalistas en Cataluña, es conveniente acotar tres conceptos fundamentales. Primero, el del fenotipo de los actores y las actrices de los spots. Segundo, el del rol principal, secundario o incidental, que desempeñan los/las protagonistas del mensaje publicitario, asociado con su fenotipo; y tercero, el de las interconexiones inclusivas o excluyentes que se observan entre protagonistas de diferentes fenotipos, en función de sus respectivos roles interpretativos.

\section{Concepto de fenotipo}

El análisis visual permite diferenciar y codificar a los protagonistas del mensaje publicitario en función de su fenotipo y supuesta afinidad genotípica, relacionada con la fisiológica y morfológica, y que viene dada, según considera Dawkins (2006), por el hecho de compartir hábitos cotidianos y dinámicas sociales y culturales similares en un mismo ambiente (climático, orográfico, geográfico, etc.). Una agrupación fenotípica que se toma como referencia fundamental en este estudio es la blanco-caucásica; la forman individuos de piel blanca (con diferentes matices del blanco) y demás rasgos del cabello, nariz, ojos (color), y de genotipo cuyo origen se considera centroeuropeo. Esta agrupación fenotípica es diferente de otras que proceden de un ambiente distinto, que ha permitido desarrollar otros rasgos fisiológicos y morfológicos. Es el caso de las migraciones provenientes de África Subsahariana, predominantemente de piel negra (de diferentes matices de este color y cabello afro), muy diferentes a las procedentes de África del Norte de origen árabe (de piel algo amarronada y cabello liso).

Consideramos que dicha afinidad fenotípica pretende identificar de manera más adecuada los/las protagonistas de los spots que la que se apunta desde la biología sobre la diferenciación por razas. En este sentido, cabe considerar lo que plantea López Beltrán sobre la doble discusión en torno a las razas humanas:

Un debate científico, en el que participan principalmente antropólogos, genetistas de poblaciones, demógrafos y algunos observadores cercanos de la ciencia. Otro debate popular, abierto, sobre si sigue cumpliendo algún fin la clasificación de los humanos en razas, y sobre si está de algún modo presupuesta en el esquema clasificatorio mismo la jerarquización racista de los grupos humanos... (2001, p. 66). 
Se descarta cualquier otra codificación de los protagonistas de los spots en función del hipotético gentilicio o supuesto grupo étnico-cultural. Se considera que si dichas adjetivaciones se aplican desde la subjetividad del codificador, se alejan de la objetividad científica (Chalmers, 2000) a la que hay que tender con este tipo de análisis destinado a constatar la representación publicitaria de la diversidad fenotípica de la sociedad catalana plural en los tiempos de crisis y cambios nacionalistas, gestionados por el poder de fenotipo blanco-caucásico.

Hay que evitar estas apreciaciones subjetivas, y más si vienen dadas por la relación de un individuo de un país con un estereotipo. Sobre ello, Baladrón (2007) establece una categorización de varios estereotipos con los que se asocia a los "otros" en la publicidad. Dos habituales son los de relacionar a los inmigrantes de ciertos países latinos u orientales con la burla o la pobreza. Es fácil hacerse una idea muy genérica sobre cómo puede ser un latino, un chino o un sudafricano, pero para verificar que estas personas son realmente de esos lugares y no adjetivarlos de manera peyorativa, hay que preguntarles y constatar si se sienten e identifican con esos lugares.

También es bastante subjetivo codificar a los protagonistas del spot de acuerdo con el uso social de raza, simplificado antaño de manera muy primaria en cinco colores de piel: blanco, negro, amarillo, cobrizo y aceitunado. Es fácil distinguir una persona de piel predominantemente blanca o clara de otra de piel negra u oscura, pero el proceso de codificación visual se complica cuando constatamos que no hay dos tonos idénticos de piel.

Algunas experiencias visuales destinadas a hacer reflexionar sobre la policromía cutánea son las que pone en práctica la fotógrafa Angélica Dass con Humanae.project (https://www.angelicadass.com/humanae-project). Aplicando la técnica Pantone, constata la diversidad infinita de tonos de piel de la humanidad. Con este tipo de ejercicios visuales es posible afirmar que cada persona tiene su propio código Pantone (https://store.pantone.com/es/es/pantone-color-institute). Probablemente esta sea la manera menos sesgada de codificar los diferentes protagonistas de los spots para no incurrir en agrupaciones condicionadas por nuestra apreciación subjetiva y estereotipada.

Ya desde 1950, la UNESCO recomienda usar la noción de etnia en vez de raza para agrupar los colectivos en función de su misma lengua, religión y ciertas costumbres históricas y tradicionales (UNESCO, 1950). Esta organización mundial considera desde entonces que es más apropiado hablar de una sola raza humana, aunque acepta que puedan darse tendencias etnocéntricas y culturales que permiten la agrupación por etnias y pueblos, como postulan desde la antropología autores como Claude Lévi-Strauss, Franz Boas y Fredrik Barth (Barth, 1969). O bien, de 
otro lado, propuestas como las del determinismo biológico, la sociobiología y el darwinismo social, favorables a la discriminación racial, defendidas por autores como Edward O. Wilson y Richard Dawkins (Templeton, 2013; Siham, 2018) y que justifican de manera genética la dominación de una élite sobre las demás especies. El determinismo ve como "normal" que determinados colectivos de origen africano sean considerados inferiores a las élites blanco-caucásicas. Algo de este tratamiento jerárquico se sigue detectando en cierta publicidad elitista. Aun así, desde la década de los 70, cada vez se le presta más atención a la incorporación de protagonistas de diferentes fenotipos en igualdad de condiciones. De todas formas, los anunciantes son bastante conservadores en este sentido, y prefieren no alterar los registros identitarios blanco-caucásicos de los intérpretes para no ver afectadas sus ventas (Wilson, Gutiérrez, \& Chao, 2003).

Estas reticencias a diversificar el protagonismo de los spots han traído como consecuencia que en los Estados Unidos los colectivos de origen africano y latino acaben produciendo e interpretando su propia publicidad, destinada a su propio consumo (Retis \& Badillo, 2015). En España, se han lanzado plataformas como la de The Black View con el fin de normalizar la incorporación de los actores de origen africano a la producción audiovisual. Al parecer, es en el casting en donde predomina un tipo de selección muy estereotipada, condicionada por la petición de los clientes o anunciantes. Según afirma Armando Buika, actor africano de piel negra: "[...] me dijeron que no era un reflejo de la sociedad porque no se ven negros policías ni abogados" (Colom, 2017).

Una referencia concreta para comprobar si la representación fenotípica de la publicidad televisiva coincide con la de la sociedad catalana plural es la de cotejar los datos demográficos del mismo año del estudio. Según datos extraídos del Instituto de Estadística de Catalunya (IDESCAT, 2018), la proporción de residentes extranjeros en Cataluña en 2014 era de 14,4\% sobre la población total, específicamente 1.085.472 residentes sobre el total de 7.518.903 registrados. Del total de residentes extranjeros, 294.360 (27,1\%) procedían de África, la mayoría, 221.605 (20,4\%), llegados de Marruecos, país en el que predomina un fenotipo que de manera genérica reúne rasgos que podríamos calificar como árabes. Le seguían Senegal, con 18.893 residentes y Gambia, con 14.812. La proporción de ambos países era tan solo de $3,1 \%$ sobre el total, por lo que se suelen ver pocos ciudadanos de este fenotipo en Cataluña que tiene como una de su característica principales la de ser de piel predominantemente negra. De América Latina, se registraron 196.772 (18,1\% del total) residentes, principalmente de Ecuador (29.514), Colombia (20.910) y Perú (29.335), lugares en los que predomina un fenotipo genérico que suele calificarse como indígena (aunque se trata de un adjetivo que ha sido muy criticado y en ocasiones es sustituido por otros no menos polémicos, como el de latino). De Asia, 
habían registrados 145.300 residentes, 13,4\% del total, venidos de China (56.030) y Pakistán (41.059). Ambos países detentan fenotipos predominantes bastantes distintos: a los primeros se les agrupa a veces con el calificativo de orientales o asiáticos, mientras que a los segundos se les suele considerar indoarios, aunque entre ellos también hay bastantes diferencias según el lugar de residencia, las etnias y las castas (Pániker, 2014). El resto de los residentes proceden de Europa, específicamente 403.105 residentes, 37,1\%, de la Unión Europea: 127.284 de Rumanía, 68.821 de Italia, 44.718 de Francia, 26.926 de Alemania y 25.813 de Reino Unido, todos ellos de fenotipo blanco-caucásico, aunque de distinta tonalidad de piel, diferentes tipos de ojos y color de pupilas, así como tipo de cabello y color, incluso diferentes formas de nariz y labios.

\section{Protagonismo principal, secundario o incidental}

Un segundo concepto es el del tipo de protagonismo de los intérpretes de diferentes fenotipos en los spots. Puede ser principal, secundario o incidental, y cabe entenderlo como un indicador fundamental para calibrar el tipo de participación del "nosotros" en comparación con la de los "otros" (Bonin, LoriteGarcía, \& Maldonado, 2016).

El personaje principal es aquel que aparece destacado más tiempo en el anuncio y sobre el que recae el hilo conductor de la trama o de la narrativa audiovisual. Se le encuadra y focaliza más que al resto mediante primeros planos, planos medios y profundidad de campo. Es, asimismo, el personaje que desempeña un rol esencial como transmisor de las virtudes comerciales del producto anunciado, el que más impacta en los consumidores y el que suele ser emulado, soñado y hasta idealizado por la sociedad de consumo en su imaginario, indistintamente de cuál sea la identidad fenotípica y cultural de los receptores/consumidores. En este sentido, Román Gubern (2002) asegura que ya desde el teatro griego se trata de protagonistas que pretenden provocar una simpátheia o empatía con sus espectadores y la identificación con sus sentimientos.

El personaje secundario es complementario al principal. Se le suele destinar bastante menos tiempo narrativo que a los protagonistas principales en el spot. Suele aparecer en composiciones corales, en planos de conjunto o generales, y si se le ve en un plano medio o primer plano suele ser de uno o dos segundos nada más. Por eso, su interpretación suele pasar casi inadvertida para los receptores del mensaje, y no le permite ser el patrón a emular ni a idealizar en su imaginario como el personaje principal.

El personaje incidental es aquel que deambula "[...] como fondo escénico sin participación significada” (Martínez, 2005, p. 4). Suele participar tan solo durante algún plano de un segundo, y si actúa durante más tiempo apenas se le destaca. 
Muchas veces es incorporado como recurso estético del mensaje publicitario. Le otorga al plano y su composición un punto de contraste sobre un todo homogéneo. A veces también suele aparecer en alguna escena como el figurante que le otorga al relato un mayor realismo o similitud con la realidad.

\section{Interconexiones}

Un criterio fundamental para comprender el tipo de comunicación que se da entre fenotipos diferentes en el spot y calibrar el posicionamiento social del discurso y el potencial efecto dinamizador que puede suscitar en la recepción plural de los mensajes es el de la interconexión estructural o coyuntural que se da entre los/las protagonistas (Lorite et al., 2018).

Consideramos que la comunicación entre los personajes es estructural cuando los protagonistas de distinto fenotipo del spot desempeñan un rol similar al social, y en absoluto se observa un tratamiento jerárquico que denote exclusión o discriminación de unos actores respecto de otros. Es un modelo de representación ficticia de la realidad cotidiana, que en apariencia funciona de manera equilibrada al desempeñar cada cual su rol con su respectiva función (sin entrar con ello a valorar si esta es la manera más justa). Es esa cotidianidad que se observa en diferentes entornos como los mercados (vendedor/a y comprador/a), las aulas (profesorado y alumnado) o los transportes públicos (conductor y viajeros/as).

La interconexión es coyuntural cuando se constata un comportamiento elitista y, por lo tanto, jerárquico y discriminador de los protagonistas de un fenotipo con relación a otro u otros. Dicho tratamiento jerárquico y elitista puede suscitar los mismos efectos discriminadores entre las audiencias plurales de los mensajes. El mensaje puede contribuir a fomentar la exclusión social, e incluso el racismo y la xenofobia. No obstante, aunque este tipo de relaciones discriminantes están cada vez más reguladas desde los códigos de conducta de organizaciones como la Mesa por la Diversidad en el Audiovisual del Consejo del Audiovisual de Cataluña (2013), AUTOCONTROL (2011) o la Cámara de Comercio Internacional (2018), que se cuidan de recomendar a los anunciantes y las agencias un tratamiento equitativo de la diversidad, sigue produciéndose bastante publicidad audiovisual en las que las personas de fenotipo blanco-caucásico son mostradas jerárquicamente superiores a las de otros fenotipos. De hecho, tal y como se verá en el análisis siguiente, casi la práctica totalidad de la publicidad televisiva se sustenta en interpretes blanco-caucásicos, y eso, ya de por sí es un indicador de la supremacía de una identidad fenotípica sobre las demás. La ausencia de diversidad puede suscitar un efecto tan sumamente excluyente de la diversidad sociocultural como el de la interconexión coyuntural o jerárquica entre los diferentes fenotipos representados en los spots. 


\section{METODOLOGÍA}

\section{Hipótesis}

La metodología va destinada a verificar y validar el planteamiento hipotético que de alguna manera ya se ha subrayado en los apartados anteriores: que la publicidad televisiva, difundida por las cadenas de mayor audiencia e impacto social, como en este caso TV3 en Cataluña, se posiciona del lado de las élites blanco-caucásicas que detentan el poder económico y político durante los tiempos de crisis económica y cambios nacionalistas en regiones geoestratégicas como Cataluña, al posicionar la representación fenotípica de sus discursos del lado casi exclusivo de la identidad fenotípica y cultural de estas élites. Por lo tanto, es una publicidad blanco-caucásica capaz de suscitar procesos de dinamización excluyentes de los colectivos de otros fenotipos e identidades culturales en vez de potenciar los procesos de dinamización intercultural inclusivos que proponen las organizaciones e instituciones reguladoras de la producción publicitaria, como la Mesa por la Diversidad en el Audiovisual del Consejo del Audiovisual de Cataluña (2013), AUTOCONTROL (2011) o la Cámara de Comercio Internacional (2018).

\section{Muestra, codificación y análisis}

Para evitar cualquier sesgo subjetivo-ideológico, según recomiendan autores como García-Ferrando, Ibáñez y Alvira (1998), en este trabajo se seleccionó una muestra cuantitativa de spots normales de marca o unidades publicitarias televisivas, difundidos por la televisión generalista Televisió de Catalunya, TV3, cadena de titularidad pública, gestionada por la Corporació Catalana de Mitjans Audiovisuals (2019), organismo coordinado por seis políticos de los principales partidos con representación parlamentaria en el Parlamento de Cataluña, que en 2014 era la de mayor audiencia y potencial impacto de los mensajes publicitarios en la opinión pública (Kantar Media, 2015). Estos índices de audiencia le permiten albergar todo tipo de campañas publicitarias, tanto las de las principales multinacionales estadounidenses, asiáticas y europeas como las de las empresas españolas y catalanas más importantes, así como la institucional y hasta la del comercio local.

Para seleccionar los spots con los criterios de homogeneidad que se requieren para efectuar adecuadamente su análisis comparativo, se partió de lo que Infoadex denomina "spots normales" o "[...] películas de diferente duración que se emiten bien entre distintos programas, bien entre los intermedios de un mismo programa y son empleadas para cualquier producto o servicio." (Infoadex, 2013, p. 16). El spot normal, al que se denomina también spot de marca o unidad publicitaria televisiva (Boninet al., 2016), va destinado a anunciar una marca o una institución y se diferencia de otras tipologías publicitarias televisivas que no se abordan en este estudio, como los publirreportajes, la publicidad sobreimpresa en la programación televisiva, las teletiendas y la autopublicidad de la cadena televisiva (Infoadex, 2013, p. 13). 
El proceso de selección de la muestra definitiva se llevó a cabo mediante la grabación y codificación de los spots de marca difundidos las 24 horas diarias de emisión de TV3 durante dos periodos objetivos del año 2014: un primero del 15/01/14 al 14/02/14, y un segundo del 15/06/14 al 14/07/14, ambos inclusive. Fueron seleccionados ambos periodos por coincidir con semanas de las rutinas cotidianas habituales de los consumidores y de la producción publicitaria. No se trató de periodos extraordinarios, como los prevacacionales o promocionales de fiestas navideñas, ni coinciden con el inicio del curso escolar o con celebraciones puntuales como el día de la madre o el padre.

Tras suprimir las piezas repetidas de una misma duración, marca y campaña, se obtuvo una muestra total de 441 spots normales de marca o unidades publicitarias televisivas. De esta primera muestra, se extrajo una submuestra de 45 spots en los que se constató que había diversidad fenotípica. De esta submuestra se seleccionaron los casos más significativos para profundizar en el análisis cualitativo, según recomiendan autores como Miles y Huberman (1994), Álvarez-Gayou (2003) y Martínez (2008), y desde elementos principales del lenguaje audiovisual como la composición de la imagen (Gubern, 1987) y el montaje (Eisenstein, 2001). Se aborda, por tanto, dicho análisis cualitativo audiovisual desde las teorías que respaldan el lenguaje audiovisual, pero a su vez desde la mirada de la cámara (Lorite García, 2017), haciendo uso de los mismos elementos narrativos y herramientas productivas que se tienen en cuenta para la realización audiovisual de los spots, específicamente el storyboard y el guion técnico (Lorite et al., 2018).

\section{ANÁLISIS CUANTITATIVO}

\section{Presencia de diversidad fenotípica en la publicidad}

La muestra obtenida de 441 spots de marca permite constatar ante todo la insignificante proporción de mensajes publicitarios con diversidad fenotípica (tabla 1). Tan solo la incorporan 45 spots de marca, es decir, uno de cada diez (10,2\%). La proporción es bastante similar en las dos oleadas: 17 spots (8,9\%) de 173 spots en la primera oleada, extraída del 15/01/14 al 14/02/14 (ambos inclusive), y 28 (11,1\%) de 223 spots en la segunda oleada del 15/06/14 al 14/07/14 (ambos inclusive).

Los datos obtenidos permiten constatar la habitual excesiva concentración de la publicidad televisiva en pocos anunciantes y, por lo tanto, el poder que detentan estas marcas en la representación y normalización de un fenotipo determinado en el imaginario de los consumidores de cualquier identidad. Es una tendencia que es posible constatar en los informes anuales sobre la inversión publicitaria en España de Infoadex (2015). En su top 20 de grupos anunciantes aparecen las mismas marcas que en la muestra analizada. Específicamente, uno de cada cuatro spots (24,5\%), 109 de 


\begin{tabular}{cccc} 
Oleadas & $\begin{array}{c}\text { Total spots } \\
\text { con diversidad }\end{array}$ & $\begin{array}{c}\text { Total spots } \\
\text { sin diversidad }\end{array}$ & $\begin{array}{c}\text { Muestra total } \\
\text { de spots }\end{array}$ \\
\hline Primera, del 15/01/14 al 14/02/14 & $17(8,9 \%)$ & $173(91,1 \%)$ & $190(100 \%)$ \\
\hline Segunda, del 15/06/14 al 14/07/14 & $28(11,1 \%)$ & $223(88,9 \%)$ & $251(100 \%)$ \\
\hline Total & $\mathbf{4 5 ( 1 0 , 2 \% )}$ & $\mathbf{3 9 6}(\mathbf{8 9 , 8 \% )}$ & $\mathbf{4 4 1 ( 1 0 0 \% )}$ \\
\hline
\end{tabular}

Tabla 1. Spots con y sin diversidad fenotípica en TV3

Fuente: Elaboración propia.

441 , pertenece a un top de 8 grandes grupos anunciantes, clasificados por este orden (entre paréntesis el número de spots): Danone (20), El Corte Inglés (17), Vodafone (13), Anefp (13), Reckitt Benckiser (13), Procter \& Gamble (12), L'Oréal (11) y McDonald’s (10).

El porcentaje de spots con diversidad fenotípica de este grupo es de tan solo 7,3\%. Únicamente se difunden ocho spots con diversidad fenotípica del total de 109 que suman el top de ocho grupos principales. La multinacional estadounidense Procter \& Gamble, anunciante de productos del hogar y de uso personal como Oral B, H\&S, Fairy, Ariel, Don Limpio, Viakal y Ambi Pur, parece algo más interesada por la representación de la diversidad fenotípica con tres spots de doce. Le siguen Danone, multinacional de productos alimenticios, con dos spots con diversidad fenotípica de 17, y Vodafone (multinacional de telefonía móvil), Anefp (multinacional de productos farmacéuticos como Bisolgrip, Mucosan, Bisolvón, Fortasec, etc.) y McDonald's (productos alimenticios) con tan solo uno de 13, 13 y 10 spots respectivamente. De este top de ocho grandes multinacionales hay tres que no usan diversidad fenotípica en sus anuncios: El Corte Inglés (red de centros comerciales españoles de venta de todo tipo de productos personales y del hogar), Reckitt Benckiser (multinacional inglesa de productos de hogar y de cuidado personal) y L'Oréal (multinacional con sede en París de productos de cuidado personal).

Dicha concentración publicitaria se sigue dando al ampliar el top de la muestra de spots a 25 marcas. En este caso, difunden un total de 215 spots, casi la mitad $(48,8 \%)$ de la muestra total de 441 spots, pero representan tan solo 15,5\% del total de 161 anunciantes de la muestra analizada. A este top de 25 se incorporan anunciantes de bastante envergadura económica en el panorama español y catalán, como las entidades bancarias CaixaBank y Bankinter, eléctricas como ENEL-ENDESA, farmacéuticas como Cederroth, marcas emblemáticas del sector alimenticio como Nestlé, supermercados como Lidl, fundaciones como la ONCE (Organización Nacional de Ciegos Españoles) con sorteos diarios, así como empresas importantes del sector automovilístico como Renault, además del mayor grupo editorial español, Planeta, e instituciones públicas como la Generalitat de Catalunya, el Ayuntamiento de Barcelona y el Gobierno de España. 


\begin{tabular}{|c|c|c|c|c|}
\hline Grupo anunciante y sector económico & $\begin{array}{c}\text { Total } \\
\text { spots }(\mathrm{N})\end{array}$ & $\begin{array}{c}\% \text { sobre el } \\
\text { total }\end{array}$ & $\begin{array}{l}\text { Spots con } \\
\text { diversidad } \\
\text { (N) }\end{array}$ & $\begin{array}{l}\% \text { spots con } \\
\text { diversidad }\end{array}$ \\
\hline Anefp (productos farmacéuticos) & 13 & 3 & 1 & 2,2 \\
\hline Ayuntamiento de Barcelona (institucional) & 7 & 1,6 & 2 & 4,5 \\
\hline Borges (aceite de oliva) & 5 & 1,1 & 0 & 0 \\
\hline Caixa Bank (entidades bancarias) & 5 & 1,1 & 0 & 0 \\
\hline Cederroth (productos farmacéuticos) & 7 & 1,6 & 0 & 0 \\
\hline Corte Inglés (centros comerciales) & 17 & 3,9 & 0 & 0 \\
\hline Danone (productos alimenticios) & 20 & 4,6 & 2 & 4,5 \\
\hline ENEL-ENDESA (compañías eléctricas) & 8 & 1,8 & 0 & 0 \\
\hline Fundación ONCE (loterías) & 5 & 1,1 & 0 & 0 \\
\hline Generalitat de Catalunya (institucional) & 7 & 1,6 & 1 & 2,2 \\
\hline Gobierno de España (institucional) & 8 & 1,8 & 1 & 2,2 \\
\hline Grup Bankinter (entidades bancarias) & 5 & 1,1 & 0 & 0 \\
\hline Grup Planeta (grupos editoriales) & 5 & 1,1 & 0 & 0 \\
\hline Grupo Vodafone (telefonía) & 13 & 3 & 1 & 2,2 \\
\hline Henkel (hogar y uso personal) & 5 & 1,1 & 0 & 0 \\
\hline L’Oréal (cuidado de la piel) & 11 & 2,5 & 1 & 2,2 \\
\hline Lidl (supermercados) & 7 & 1,6 & 1 & 2,2 \\
\hline McDonald's (alimentación) & 10 & 2,3 & 1 & 2,2 \\
\hline Nestlé (alimentación) & 8 & 1,8 & 0 & 0 \\
\hline Orange - Amena (telefonía móvil) & 8 & 1,8 & 1 & 2,2 \\
\hline Procter \& Gamble (hogar y uso personal) & 12 & 2,7 & 3 & 6,7 \\
\hline Reckitt Benckiser (hogar y uso personal) & 13 & 3 & 0 & 0 \\
\hline Renault (automóvil) & 6 & 1,4 & 0 & 0 \\
\hline Securitas (seguros) & 5 & 1,1 & 0 & 0 \\
\hline Volkswagen (automóvil) & 5 & 1,1 & 0 & 0 \\
\hline Total parcial & 215 & 48,8 & 15 & 33,3 \\
\hline Total restante & 226 & 51,2 & 30 & 66,7 \\
\hline Total muestra & 441 & 100 & 45 & 100 \\
\hline
\end{tabular}

Tabla 2. Spots con diversidad fenotípica en el top de los 25 principales grupos anunciantes y sector económico en TV3

Fuente: Elaboración propia. 
Es posible constatar que en este top de 25 anunciantes la proporción de spots con diversidad es similar (6,9\%) al top de ocho (7,3\%). Tan solo difunden 15 spots con diversidad fenotípica del total de 215. Esto quiere decir que únicamente emiten uno de cada tres anuncios con diversidad $(33,3 \%)$ de la submuestra total de 45 . Se constata que anunciantes importantes como Volkswagen, Borges, ENEL, Henkel, Securitas, CaixaBank, Bankinter, Grupo Planeta, Cederroth, Renault o Fundación ONCE, no incorporan fenotipos distintos al blanco-caucásico en sus anuncios. A este top de 25 se incorpora el Gobierno de España con un spot con diversidad de ocho, la Generalitat de Cataluña con uno de siete, y el Ayuntamiento de Barcelona, con dos de siete. De las empresas privadas, solo se agregan al top de ocho grandes marcas que copan el $24,5 \%$ de la publicidad la multinacional alemana Lidl con un spot con diversidad de un total de siete y la multinacional francesa Orange-Amena, también con uno de un total de ocho.

\section{Protagonismo de la diversidad}

En 25 spots, más de la mitad de la submuestra de 45 spots con diversidad fenotípica, el protagonismo principal recae igualmente sobre intérpretes blancocaucásicos. En tan solo 20 spots (45,5\%) de los 45 con diversidad los intérpretes de otros fenotipos adquieren el rol de protagonistas principales sobre los que gira la trama central del discurso articulado. Se trata de una insignificante proporción de $4,5 \%$ si se calcula sobre el total de 441 spots normales de marca de la muestra total. Esto quiere decir que el $95,5 \%$ restante está protagonizado exclusivamente por interpretes blanco-caucásicos, y que la publicidad se inclina casi totalmente hacia la homogeneidad identitaria propia del "nosotros" y lo "nuestro" en los tiempos de crisis económica y cambios nacionalistas que coinciden en Cataluña en el 2014.

Principalmente son las multinacionales estadounidenses Red Bull, Calvin Klein, H\&S, Herbal Essences, Oral B y McDonald's, y algunas multinacionales europeas como Kinder, Danone, Lidl, Mini y Orange, las que recurren a actores y actrices de fenotipo diferente al blanco-caucásico como referentes destacados de la marca y de sus productos, aunque, como se ha visto en el análisis cuantitativo, es en proporciones casi insignificantes. En el caso de Red Bull se apela a ciertos atletas afroamericanos que practican los deportes de riesgo patrocinados por la marca. En el del anuncio de McDonald's se incorpora el fenotipo de procedencia africana de la tercera parte de habitantes de Luisiana, para mostrarlos en una sesión de jazz y un combate de boxeo. Paradójicamente, se trata de un fenotipo que no coincide con los de la migración europea, francesa y blanco-caucásica, que introduce la salsa cajún en los Estados Unidos (Paige, 1992), anunciada por la marca para promocionar sus hamburguesas, sino con las otras migraciones llegadas con el esclavismo africano que al parecer es con la que asocia el imaginario este lugar de los Estados Unidos, construido mediante el lenguaje cinematográfico. 
En el spot de la multinacional estadounidense Calvin Klein, perteneciente al grupo PVH Corporation, con sede en Manhattan, Nueva York, se apuesta por una diversidad fenotípica juvenil, inspirada en las tribus urbanas, para conectar: “[... con la nueva estética minimalista, andrógina e industrial de la llamada generación X" (Calvin Klein, 2019). Los productos H\&S, Herbal Essences y Oral B de la multinacional estadounidense Procter \& Gamble, fundada por los ingleses William Procter y James Gamble en 1837 y con sede central en Ohio, apuestan por celebridades como Sofía Vergara y Shakira. En este caso, se apela al estereotipo de mujer latina exótica de cierto mestizaje de predominio blanco-caucásico (Brooks \& Hébert, 2006).

Los spots de las empresas e instituciones españolas y catalanas no usan como protagonistas principales a actores de fenotipo diferente al blanco-caucásico. Tan solo se encuentran dos spots, uno de la cerveza San Miguel, empresa con sede central en Barcelona, de dos duraciones diferentes, uno de 60 segundos y otro de 40, en los que se entrelazan protagonistas de diferentes fenotipos al son de una misma canción, A Place Called World, en consonancia con el eslogan de la campaña Un lugar llamado mundo (San Miguel, 2014). En la secuencia inicial de los dos anuncios se puede ver a John Legend, cantante estadounidense afroamericano, nacido en Springfield, Ohio, presentando la canción y compartiendo protagonismo con otros músicos españoles como Anni B.Sweet, Nach, The Zombie Kids e ingleses como Dan Croll, de otros estilos musicales como el indie rock, beats y rap, pero todos ellos de fenotipo blanco-caucásico.

El otro spot televisivo con protagonista principal de fenotipo diferente al blancocaucásico es el de Voltem per Catalunya (Mediaq.tv, 2014), anuncio destinado a promocionar el comercio local, presentado por Asha Miró, mujer nacida en Nasik, India, que llegó a Barcelona en 1974 al ser adoptada por una familia catalana (Torres, 2014). Se puede ver a esta mujer en un plano medio al inicio del anuncio, presentando en un catalán estándar, similar al que usan habitualmente las presentadoras de informativos de TV3, diferentes propuestas comerciales locales.

Tampoco se suple el vacío de protagonistas principales de fenotipos diferentes al blanco-caucásico, con la participación como personajes secundarios. Tan sólo se constata esta participación en seis spots de la muestra total de 45 con diversidad: cuatro de multinacionales europeas (Ikea, Nestlé-Maxibon, San Pellegrino y Amena), uno de la multinacional japonesa Nissan y tan solo uno de Cataluña correspondiente al Ayuntamiento de Barcelona. Aparecen como secundarios de otros fenotipos un equipo de fútbol de niños de un país turístico, supuestamente Marruecos, visitado por el protagonista principal blanco-caucásico, que comparten foto con él en el anuncio de Ikea; el de un joven de fenotipo africano y pelo afro 


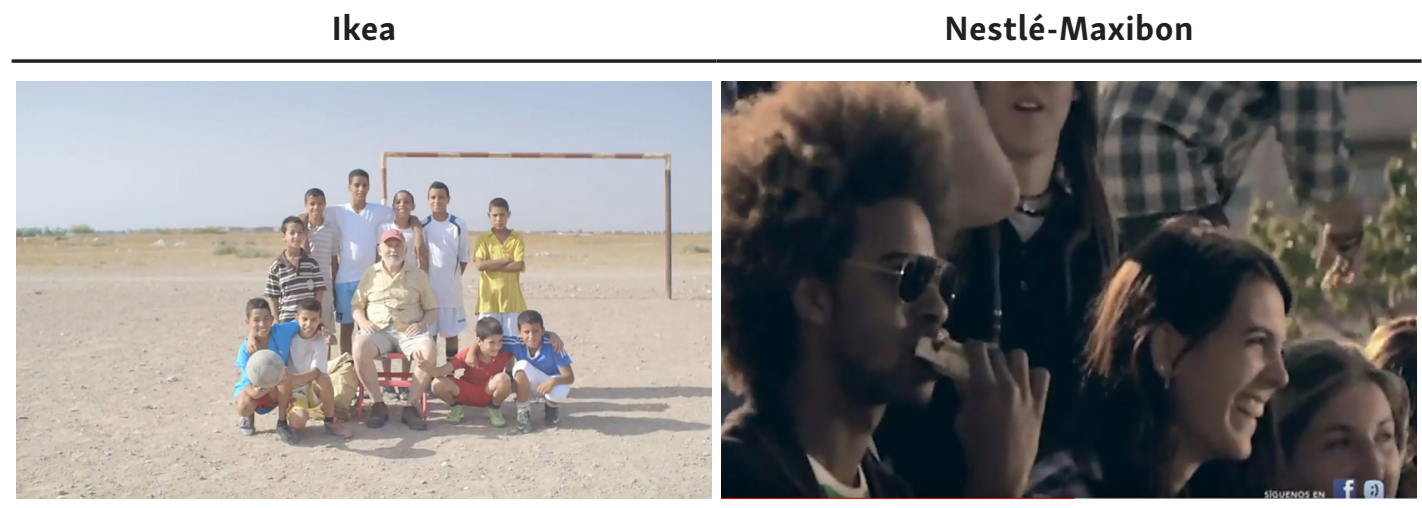

San Pellegrino

Amena
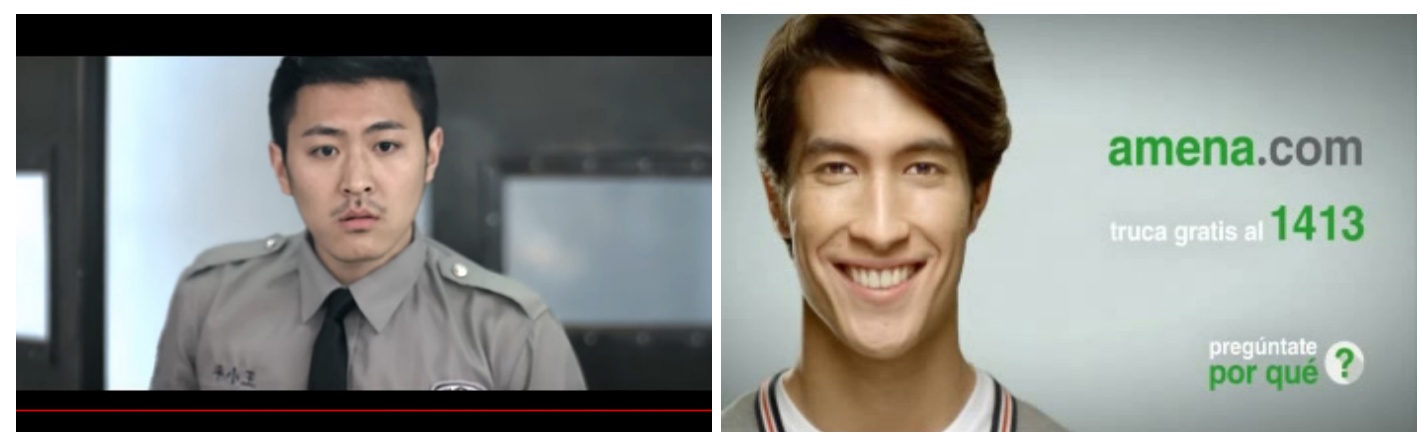

Nissan

Ayuntamiento de Barcelona
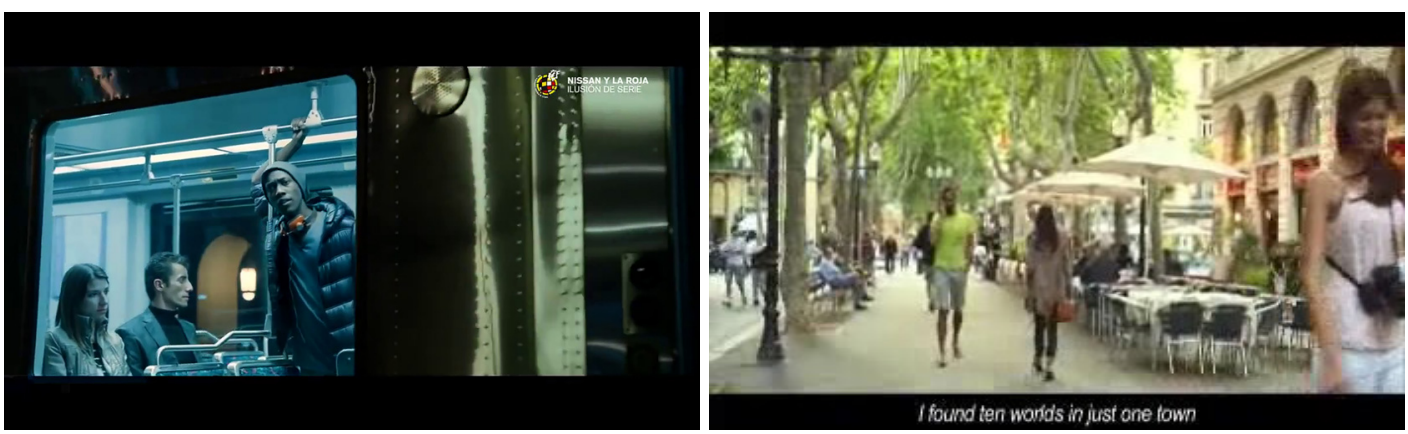

Ilustración 1. Protagonistas secundarios de fenotipos diferentes al blanco-caucásico

Fuente: Elaboración propia con base en los spots publicitarios de lkea, Nestlé-Maxibon, San Pellegrino, Amena, Nissan y Ayuntamiento de Barcelona.

deleitándose con el helado Maxibon de Nestlé; el de un hombre de fenotipo propio de Singapur en el anuncio de San Pellegrino; el hombre de rasgos orientales de Amena, aunque también de otros rasgos faciales bastantes occidentales; el hombre de fenotipo africano que viaja de pie en el metro del anuncio de Nissan, y el hombre, apenas perceptible, pero que podría ser de fenotipo propio de oriente, que camina por la Rambla del Poblenou de Barcelona en el anuncio del Ayuntamiento de Barcelona sobre la campaña promocional de la ciudad (ilustración 1). 
Esclerosis Múltiple

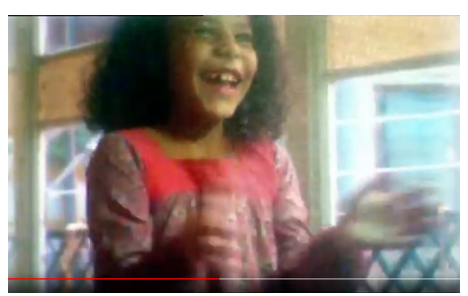

Cacaolat

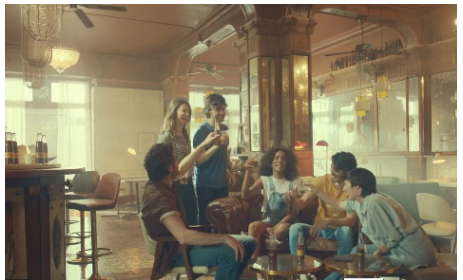

Gobierno de España

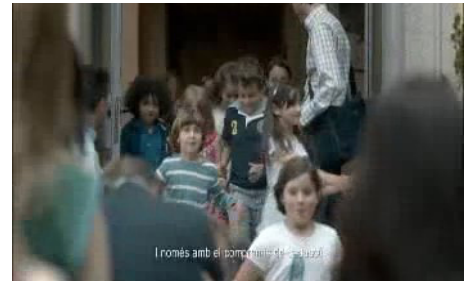

Ilustración 2. Cabello afro en los "otros" protagonistas

Fuente: Elaboración propia con base en los spots publicitarios de Esclerosis Múltiple, Cacaolat y Gobierno de España.

En cuanto a la participación de personajes incidentales de fenotipo diferente al blanco-caucásico, es tan insignificante como la presencia de secundarios y principales. Aparece algún personaje incidental durante un plano de un segundo y de manera casi imperceptible en 14 spots $(31,1 \%)$ de la submuestra de 45 spots con diversidad.

La práctica totalidad de estas apariciones incidentales suele ser en anuncios de multinacionales estadounidenses o europeas. Es el caso de unas mujeres afroamericanas desfilando por Nueva Orleans en el anuncio de McDonald's sobre la salsa cajú; el de un joven de fenotipo oriental detrás del protagonista del anuncio de Smint en un supermercado; el de un hombre de fenotipo africano en una terraza en el spot de Amena, y el de dos trabajadores orientales de un hotel de Singapur en el anuncio de San Pellegrino.

En el caso de la publicidad de empresas e instituciones españolas y catalanas, el inapreciable protagonismo de los "otros" fenotipos se relega al grafismo. Es posible constatarlo con el spot de la Revista de la Liga Endesa, destinada al campeonato estatal español de baloncesto, en el que se ve a un jugador de fenotipo africano destacando al fondo entre el resto de jugadores blanco-caucásicos. También se usa este recurso gráfico en el spot de Laboratorios Ferrer, en donde se ve a una niña de fenotipo oriental en la etiqueta de la caja del producto anunciado. Asimismo, en el anuncio de la revista promocional de la programación infantil de TV3, Club Super3, se divisa un actor secundario de fenotipo afroamericano detrás de los protagonistas principales, blanco-caucásicos, de la serie juvenil House of Onubis, producida y distribuida por Nickelodeon en los Estados Unidos.

Un rasgo común de los protagonistas de los "otros" fenotipos, y en particular de los incidentales, suele ser el tipo de cabello rizado conocido con el calificativo de afro. Se acude a este tipo de rasgo identitario diferencial en el spot de la campaña sobre la Esclerosis Múltiple para mostrar en un plano de un segundo a una niña alegre saltando; en el de Cacaolat una mujer con este cabello entre el grupo de amigos blanco-caucásicos, y en el del Gobierno de España, un niño de fenotipo claramente distinto a los demás saliendo de la escuela (ilustración 2). 


\section{Interconexión de los protagonistas}

Tan solo se observa algún tipo de interconexión entre personajes de fenotipos diferentes en uno de cada tres anuncios con diversidad, específicamente en 15 $(33,3 \%)$ de 45 spots, una proporción que representa tan solo 3,4\% del total de 441 anuncios de la muestra total analizada. Es, por lo tanto, una contribución prácticamente insignificante de la publicidad televisiva a representar situaciones en las que se pueda suscitar la potencial dinamización inclusiva o excluyente de los receptores/consumidores de diferentes identidades.

No obstante, el tipo de interconexión entre protagonistas de distintos fenotipos es estructural. Vemos como interactúan con total normalidad, desempeñando cada cual su rol y sin observarse ninguna actitud jerárquica o discriminadora entre ellos. Aun así, habría que diferenciar propuestas de interacción de celebridades con su entorno elitista, como la que se constata en el anuncio H\&S, con Sofía Vergara, representando estar en una fiesta familiar en una mansión de lujo y portando peinados y vestuarios de moda de alto standing, de otras como las de Vitalinea o Residencia Àgora Barcelona, en las que las acciones se desarrollan en entornos cotidianos como una sala de baile y un gimnasio, y las protagonistas van vestidas y peinadas de la manera estándar habitual de estos espacios, sin denotar un tipo de pertenencia a una clase social determinada.

\section{ANÁLISIS CUALITATIVO}

Una de las maneras de comprobar de manera cualitativa si la publicidad televisiva contribuye a representar la sociedad catalana plural o se inclina hacia el fenotipo blanco-caucásico propio del poder en los tiempos de crisis y cambios nacionalistas, es mediante el análisis cualitativo de los spots de instituciones públicas como la Generalitat de Catalunya (Gobierno de Cataluña) y el Ayuntamiento o Casa Consistorial de la Ciudad de Barcelona.

Ante todo, llama la atención que tan solo se difunda un spot con diversidad fenotípica de la Generalitat y dos del Ayuntamiento de Barcelona, de los siete que se obtienen de cada institución en la muestra total analizada de 441 spots normales de marca. Pero además se constata que no optan por representar la diversidad fenotípica real de la ciudad o de la región a la que se dirigen, y que en los pocos planos en los que aparecen protagonistas de otros fenotipos, estos suelen desempeñar un papel secundario o incidental, meramente testimonial, que apenas permite apreciar la presencia de dicha diversidad en el producto audiovisual ni de homologarla con la pluralidad fenotípica de la sociedad catalana de ese momento. 


\section{CatSalut Respon de la Generalitat de Catalunya}

En el caso de la Generalitat de Catalunya, se trata de un anuncio de 40 segundos de la campaña de CatSalut Respon, destinado a informar a todos los catalanes, de cualquier identidad y procedencia, sobre el funcionamiento del equipo de atención de "metges, infermeres i tècnics".

En las imágenes seleccionadas del spot (ilustración 3) podemos comprobar cómo el hombre ubicado en el spot en una primera secuencia, entre otras dos protagonistas secundarias, una supuesta cliente del servicio como él (imagen a su izquierda), y una técnica del servicio (imagen abajo a continuación), parece detentar un fenotipo diferente al blanco-caucásico de ellas y al de la protagonista principal, Helena García Melero, periodista de TV3, presentadora de espacios informativos y de entretenimiento, que se ve en la segunda fila, a la derecha, explicando in situ el funcionamiento del servicio. Los rasgos faciales de este hombre (cejas, ojos, boca, tono de piel, cabello, barba, etc.) son diferentes a los de ellas. Podrían ser considerados como propios de cualquier país árabe del Mediterráneo africano. Podría tratarse de un ciudadano más de la importante comunidad de origen marroquí residente en Cataluña.

La composición visual del hombre es idéntica a la de la primera mujer. No hay discriminación visual en este caso, como suele ser habitual con el tratamiento televisivo de la inmigración en la información, por ejemplo. El "otro" siempre se ve lejos, en planos generales, la fuente oficial cerca en primer plano o plano medio (Sendín, 2008). Se trata de un primer plano de la mujer que sucede a otro primer plano, y ambos encuadres permiten acercarse a los dos personajes y simular que se dialoga con ellos. El hombre da su opinión sobre el servicio médico mirando a la cámara, simulando mirar a los ojos. Lo hace en un catalán estándar, sin acento marroquí. No se da ninguna interconexión hombre/mujer. De la supuesta usuaria blanco-caucásica se pasa, mediante una transición por corte, al hombre de fenotipo árabe, y deél, por corte también, a la mujer blanco-caucásica del servicio de asistencia. Se puede afirmar, por lo tanto, que esta modalidad de montaje mediante transición por corte no permite suscitar el efecto dinamizador inclusivo (o excluyente) de otros anuncios en los que los protagonistas aparecen interactuando entre ellos en el mismo plano de acuerdo con los modelos de interconexión estructural o coyuntural.

Tras la primera secuencia del hombre de fenotipo diferente al de las mujeres blanco-caucásicas, se pasa a una segunda en la que se muestran las oficinas del servicio de asistencia. El fenotipo de los protagonistas incidentales que aparecen

1. "Médicos, enfermeras y técnicos". Llama la atención que se les denomine así, por este orden y mediante este tratamiento de género. 

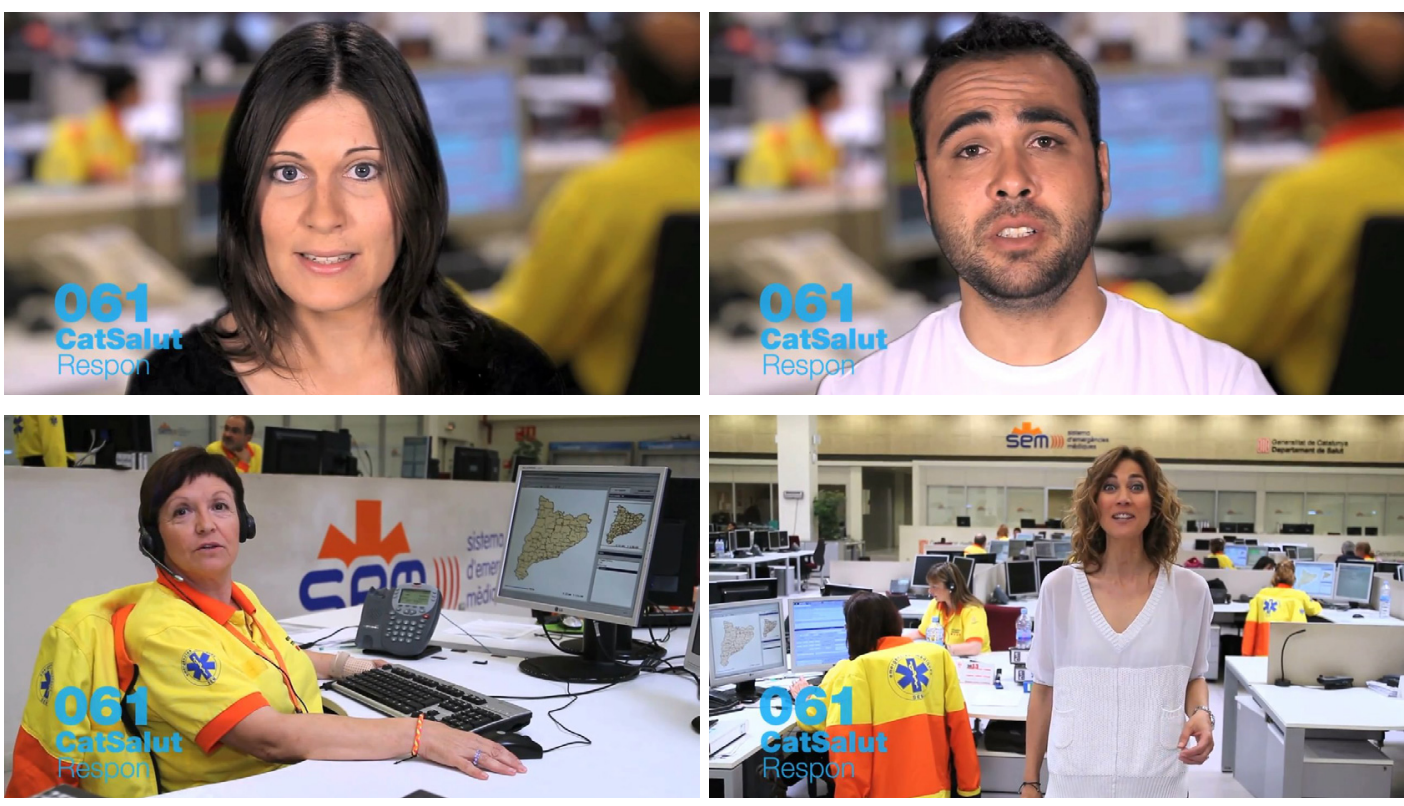

Ilustración 3. Imágenes seleccionadas del spot de la campaña de CatSalut Respon. Generalitat de Catalunya, 2014

Fuente: Elaboración propia con base en Generalitat de Catalunya.

en este lugar permite constatar que todos son blanco-caucásicos. No se observa diversidad fenotípica. Cabe preguntarse si es un fiel reflejo de la realidad de ese espacio, y en caso de que así sea si ha de ser este el criterio para representar la realidad plural que debe poner en práctica el Gobierno de Cataluña para informar de un servicio público, como este, destinado a toda la población, indistintamente de cuál sea su procedencia, identidad cultural o color de piel.

\section{Viu una ciutat i descobreix-ne 10, campaña del Ayuntamiento de Barcelona}

Al igual que la publicidad institucional anterior, pero en este caso desde la campaña promocional de Barcelona ciudad, difundida por el ayuntamiento, mediante el eslogan Viu una ciutat $i$ descobreix-ne $10^{2}$, tampoco se muestra una ciudadanía real acorde con la diversidad fenotípica que reside en esta metrópolis.

Al igual que en el anuncio de la Generalitat, la presentadora es blanco-caucásica. Llama la atención que este tipo de publicidad municipal muestre tan solo la ciudad arquitectónica e histórica. La protagonista pasea por Barcelona, pero no interactúa con los ciudadanos. Tan solo se da un tipo de comunicación simpática con una pareja de vecinos, blanco-caucásicos, del barrio de Gracia (ilustración 4), dando a entender que podría ser el único tipo de vecindad de este lugar, siendo que se trata de uno de los barrios más multi e interculturales de la ciudad.

2. "Vive una ciudad y descubre 10". El número 10 se refiere a los distritos en los que se estructura a nivel urbano la ciudad. 


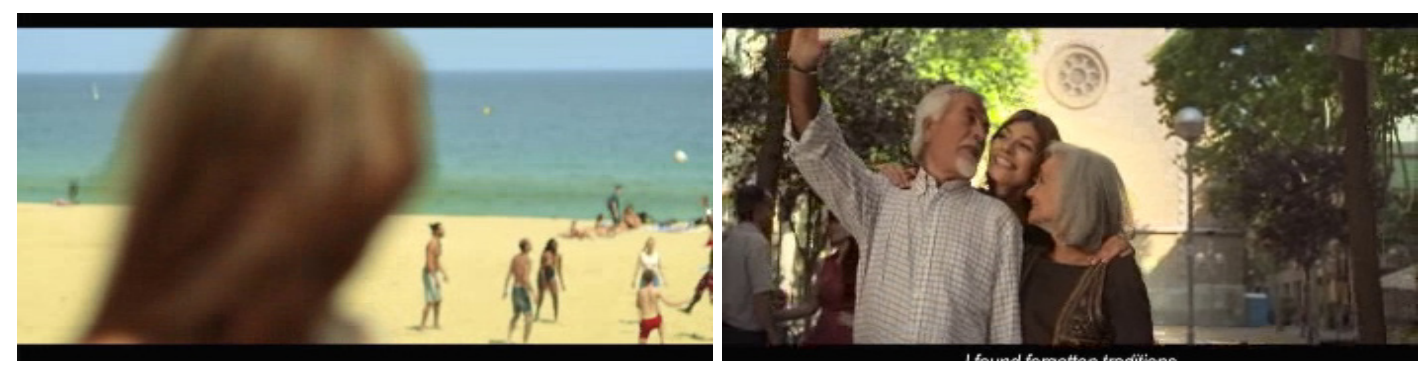

Ilustración 4. Dos imágenes del spot de la campaña Viu una ciutat i descobreix-ne 10, 2014

Fuente: Elaboración propia con base en el spot publicitario del Ayuntamiento de Barcelona.

Únicamente se puede atisbar algo de la diversidad barcelonesa real en un plano de menos de un segundo del total de 60 segundos que dura el spot, durante una primera secuencia en la que la protagonista pasea por la playa de la Barceloneta de la ciudad y se detiene a ver cómo juegan al voleibol unos bañistas, entre los que se ven a lo lejos, en un plano general (que apenas se aprecia si se visiona el anuncio sin pausarlo), una mujer y dos hombres de fenotipos distintos al blancocaucásico de la protagonista principal.

En la misma campaña se encuentra un segundo anuncio de 20 segundos de duración, destinado a uno de los diez distritos de la ciudad, el de Sant Martí y HortaGuinardó, en el que, durante la primera secuencia de tres segundos, se observa a un hombre de fenotipo diferente a la protagonista, probablemente indoario (Pániker, 2014), caminando por una rambla o paseo de la zona (ver imagen en la ilustración 1). Aun así, es un plano general en el que se ve a lo lejos y no permite representar este lugar con la diversidad cotidiana real habitual.

\section{CONCLUSIONES}

Mediante el análisis cuantitativo de una muestra de 441 spots de marca y cualitativo de dos casos representativos de la publicidad institucional de Cataluña (Generalitat de Catalunya y Ayuntamiento de Barcelona), se puede constatar que la publicidad difundida por TV3, la cadena televisiva pública de mayor audiencia e impacto social en Cataluña, se decanta casi en su totalidad $(95,5 \%)$ por una representación fenotípica blanco-caucásica. Esto está en consonancia con el modelo cultural homogéneo elitista que gestiona el poder económico y los cambios políticos en los tiempos de crisis defensivos de lo "nuestro" y nacionalistas independentistas del "nosotros" de "aquí", pero no con el de la diversidad fenotípica de la sociedad catalana en una región geoestratégica clave del Mediterráneo como Cataluña, en 2014.

También se ha verificado cómo la exclusión de la diversidad fenotípica viene dada por el hecho de que el top de anunciantes que difunden más spots, y por lo 
tanto destinan un mayor presupuesto a la publicidad televisiva, en particular las multinacionales internacionales Danone, Vodafone, Anefp, Reckitt Benckiser, Procter \& Gamble, L'Oréal, McDonald's, Lidl y Nissan, apuestan casi exclusivamente por el fenotipo blanco-caucásico como valor comercial seguro.

En tan solo uno de cada diez spots de marca el mensaje publicitario incorpora protagonistas de fenotipos diferentes al blanco-caucásico, pero incluso en esta submuestra de 45 spots con diversidad el protagonismo también recae principalmente en interpretes blanco-caucásicos. Es, por lo tanto, una representación de la diversidad fenotípica casi insignificante, muy inferior al $14,4 \%$ de residentes extranjeros registrados en 2014 en Cataluña, que no tiene en cuenta a los colectivos inmigrantes más numerosos, como los marroquíes, que representan 20,4\% del total de residentes extranjeros, ni de otros fenotipos como los propios de la inmigración latinoamericana. Las multinacionales estadounidenses acuden a celebridades de Colombia, como Shakira o Sofía Vergara, pero más por su exotismo que por su identidad fenotípica.

Esta escasa representación de la diversidad fenotípica en la publicidad televisiva lleva a que también sea prácticamente insignificante la proporción de spots con interconexiones entre protagonistas de diferentes fenotipos, que es, como se ha señalado en el marco teórico, un indicador fundamental del potencial efecto dinamizador intercultural inclusivo del mensaje. Aun así, se verifica que las pocas interconexiones encontradas son estructurales y no coyunturales, y que por lo tanto muestran una relación igualitaria y no discriminatoria del fenotipo blancocaucásico hacia los "otros".

Es conveniente subrayar, por último, que los datos cuantitativos y cualitativos mostrados en este artículo están destinados a evaluar la función dinamizadora intercultural de mensajes tan sumamente impactantes en la sociedad catalana como los publicitarios, desde modelos de investigación-acción e investigación audiovisual aplicada (Lorite et al., 2018), que persiguen vincular investigación y docencia universitarias con la profesión publicitaria, en particular con sus organizaciones como el Colegio de Publicitarios y Relaciones Públicas de Cataluña, y los órganos de regulación del lenguaje mediático inclusivo como la Mesa por la Diversidad del Audiovisual del Consejo del Audiovisual de Cataluña (2013). Todo lo anterior con el objetivo de equilibrar la representación de la diversidad fenotípica en la publicidad con la pluralidad de la sociedad catalana y evitar que el mensaje publicitario se posicione únicamente del lado de las élites económicas y políticas blanco-caucásicas, tanto en los tiempos de crisis y cambios en los que se analiza en este trabajo, tendientes a la radicalización, como en futuros momentos de bonanza económica y nuevas remesas migratorias internacionales. 


\section{REFERENCIAS}

Abdelal, R., Yoshiko, M. H., Alastair, I. J., \& Rose, M. (2009). Measuring identity. A guide for social scientists. New York, NY: Cambridge University Press.

Álvarez-Gayou, J. L. (2003). Cómo hacer investigación cualitativa. Fundamentos y metodología (How to do qualitative research. Fundamentals and methodology). Mexico City, Mexico: Paidós Mexicana.

AUTOCONTROL. (2011). Código de conducta publicitaria (Code of advertising behavior). Madrid, Spain: AUTOCONTROL. Retrieved from https://www.autocontrol.es/codigos-de-conducta/

Ayuntamiento de Barcelona. (2014, July 11). Viu una ciutat $i$ descobreix-ne 10 (Live a city and discover 10) (video). Retrieved from https://www.youtube.com/watch?v=EvF9znoPN_s

Baladrón, A. J. (Coord.) (2007). La Publicidad se acerca a la inmigración: un factor de integración de la diversidad (Advertising approaches immigration: a factor of integration of diversity). Madrid, Spain: Observatorio de las Realidades Sociales y de la Comunicación.

Barth, F. (1969). Ethnic groups and boundaries. The social organization of culture difference. Illinois, IL: Waveland Press, INC.

Benavides, J. (1995). La presencia de la publicidad en la construcción de la cultura y la identidad (The presence of advertising in the construction of culture and identity). Estudios sobre consumo, (35), 43-65.

Benavides, J. (1997). Lenguaje publicitario: hacia un estudio del lenguaje en los medios (Advertising language: towards a study of language in the media). Madrid, Spain: Síntesis.

Bonin, J., Lorite-García, N., \& Maldonado, E. (2016). Publicidad, propaganda y diversidades socioculturales (Advertising, propaganda and sociocultural diversities). Quito, Ecuador: CIESPAL.

Brooks, D.E., \& Hébert, L.P. (2006). Gender, Race, and Media Representation. In B. J. Dow \& T. J. Wood (Eds.), The Sage Handbook of Gender and Communication. London, UK: SAGE.

Calvin Klein. (2014).Perfumative. CKONE. Retrieved from https://perfumative.es/ck-one-calvin-klein/

Cámara de Comercio Internacional. (2018). Código de Publicidad y de Comunicaciones de Mercadeo (Advertising and Marketing Communications Code). Paris, France: International Chamber of Commerce (ICC).

Castells, M. (2001). La Era de la Información. Economía, Sociedad y Cultura. Vol. 2. El poder de la Identidad (The age of information. Economy, Society and Culture. Vol. 2. The power of Identity). Madrid, Spain: Alianza Editorial.

Castelló, E. (2008). Identidades mediáticas. Introducción a las teorías, métodos y casos (Media identities. Introduction to theories, methods, and cases). Barcelona, Spain: UOC.

Centre d'Estudis Demogràfics. (2019). Migracions internacionals (International migrations). Retrieved from https://ced.uab.cat/area-recerca/migracions-internacionals/

Colom, M. (2017, March 14). Armando Buika: "En un casting me dijeron que no era un reflejo de la sociedad porque no se ven negros policías ni abogados" (Armando Buika: "In A casting I was told that it was not a reflection of society because you do not see black cops or lawyers"). Wiriko. Retrieved from https://www.wiriko.org/cine-audiovisuales/the-black-view/ 
Corporació Catalana de Mitjans Audiovisuals. (2019). Organs de Govern (Government organs). Retrieved from https://www.ccma.cat/corporatiu/es/com-funciona/organs-govern/

Curran, J., Morley, D., \& Walkerdine, V. (1996). Estudios culturales y comunicación (Cultural Studies and Communication). Barcelona, Spain: Paidós.

Chalmers, A. (2000). ¿Qué es esa cosa llamada ciencia? (What is that thing called science?). Madrid, Spain: Siglo XXI.

Dawkins, R. (2006). El fenotipo extendido (The extended phenotype). Madrid, Spain: Capitan Swing.

Domingo, A. (2019). De la utopía generacional a la distopia demográfica (1968-2018) (From the generational utopia to the demographic disorder (1968-2018)). L'Espill, (59), 87-99. Retrieved from https://www.uv.es/lespill/actual.html

Eisenstein, S. M. (2001). Hacia una teoría del montaje, Vol.2. (Towards an editing theory, 2nd vol.). Barcelona, Spain: Paidós.

García, L. (2018). El naufragio. La deconstrucción del sueño independentista (The shipwreck. The deconstruction of the independence dream). Barcelona, Spain: Ediciones Península.

García Canclini, N. (1989). Culturas Híbridas (Hybrid cultures). Mexico City, Mexico: Grijalbo.

García Ferrando, M., Ibáñez J., \& Alvira, F. (1998). El análisis de la realidad social. Métodos y técnicas de investigación (The analysis of social reality. Research methods and techniques). Madrid, Spain: Alianza Universidad.

Gubern, R. (2002). Máscaras de la ficción (Fiction masks). Barcelona, Spain: Anagrama.

Gubern, R. (1987). La mirada opulenta. Exploración de la iconosfera contemporánea (The opulent gaze. An exploration of contemporary icone - sphere). Barcelona, Spain: Gustavo Gili.

Hall S. \& Gay P. du (comps.) (1996). Cuestiones de identidad cultural (Cultural Identity Questions). Buenos Aires, Argentina: Amorrortu.

IDESCAT. (2018). Anuario estadístico de Cataluña (Catalonian Statistical Yearbook) (data set). Retrieved from http://www.idescat.cat/pub/?id=aec\&n=245\&lang=es

Infoadex.(2013). Libro Técnico 2013 (2013 Technical Book). Madrid, Spain: Infoadex.

Infoadex. (2015). Estudio InfoAdex de la Inversión Publicitaria en España 2014 (2014 InfoAdex Study of Advertising Investment in Spain). Madrid, Spain: Infoadex.

Kantar Media. (2015). Anuario de Audiencias 2015 (2015 Audience Yearbook). Madrid, Spain: Kantar Media.

López Beltrán, C. (2001). Para una crítica de la noción de raza (For a critique of the notion of race). Ciencias, (60), 98-106. Retrieved from http://www.revistaciencias.unam.mx/ es/95-revistas/revista-ciencias-60/808-para-una-critica-de-la-nocion-de-raza.html

Lorite García, N., Grau Rebollo, J., \& Lacerda J. (2018). Representation of sociocultural diversity in audiovisual advertising: materials for inclusive treatment. Revista Latina de Comunicación Social, (73), 425-446. https://doi.org/10.4185/RLCS-2018-1263en 
Lorite García, N. (2017). La cámara como herramienta principal para la investigación audiovisual aplicada de la diversidad en la publicidad televisiva (The camera as the main tool for applied audiovisual research on diversity in television advertising). In J. Sierra (Coord.), Nuevas tecnologías audiovisuales para nuevas narrativas interactivas digitales en la era multidispositivo. Vol 1. (New audiovisual technologies for new digital interactive narratives in the multi-device era. Vol. 1.) (pp. 104-122). Madrid, Spain: Mc Graw Hill.

Martínez, R. (2005). Interculturalidad y publicidad (Interculturality and advertising). Mugak, 30, 1-11. Retrieved from http://mugak.eu/revista-mugak/no-30/ interculturalidad-y-publicidad

Martínez, P. (2008). Cualitativa-mente. Los secretos de la investigación cualitativa (Qualitatively. The secrets of qualitative research). Madrid, Spain: MillwardBrowm, ESIC.

Mediaq.tv (2014, Juny 12). Voltem per Catalunya Cap. 3 (Let's walk around Catalonia Chapter 3) (video). Retrieved from https://vimeo.com/98628248

Mesa per la Diversitat en l'Audiovisual, Consell de l'Audiovisual de Catalunya. (2013). El discurs mediàtic sobre la immigració a Catalunya. Reflexións per a la consecució d'un llenguatge inclusiu (The media discourse on immigration in Catalonia. Reflections for the achievement of an inclusive language). Retrieved from https://www.mesadiversitat.cat/materials/discursmediatic-la-immigracio-catalunya-reflexions-la-consecucio-dun-llenguatge-inclusiu

Miles M. \& Huberman M. (1994). Qualitative data analysis. London, UK: Sage.

Paige, C. (1992). Cajun Foodways. Mississippi, MS: University Press of Mississippi.

Pajares, M. (2006). Procesos migratorios e integración socio-laboral de los inmigrantes rumanos en Cataluña (Migratory processes and socio-labor integration of Romanian immigrants in Catalonia). Doctoral dissertation. Retrieved from http://hdl.handle.net/10803/707

Pániker, A. (2014). La sociedad de castas (The caste society). Barcelona, Spain: Kairós.

Parella, S. \& Petroff, A. (2014). Migración de retorno en España: salidas de inmigrantes y programas de retorno en un contexto de crisis (Migration of return in Spain: immigrants' outflows and return programs in a crisis context ). In J. Arango, D. Moya Malapeira, \& J. Oliver Alonso (Dir.), Inmigración y Emigración: mitos y realidades. Anuario de la Inmigración en España 2013 (Immigration and emigration: myths and realities. 2013 Yearbook of Immigration in Spain). Barcelona, Spain: CIDOB. Retrieved from https://www.cidob.org/ articulos/anuario_cidob_de_la_inmigracion/2014/migracion_de_retorno_en_espana_salidas_ de_inmigrantes_y_programas_de_retorno_en_un_contexto_de_crisis

Retis, J. \& Badillo, A. (2015). Los latinos y las industrias culturales en español en Estados Unidos (Latinos and cultural industries in Spanish in the United States). Madrid, Spain: Real Instituto Elcano. Retrieved from http://www.realinstitutoelcano.org/wps/portal/rielcano_ es/contenido?WCM_GLOBAL_CONTEXT=/elcano/elcano_es/zonas_es/lengua+y+cultura/ dt01-2015-retis-badillo-latinos-industrias-culturales-en-espanol-en-eeuu

Rodrigo Alsina, M. (2000). Identitats i comunicación intercultural (Identities and intercultural communication). Barcelona, Spain: Edicions 3 i 4.

San Miguel. (2014). Un lugar llamado mundo (A place called the world) (video). Retrieved from https://www.youtube.com/watch?v=tQM8KqYOXxY 
Sendín, J. C. (2008). Guía práctica para los profesionales de los medios de comunicación. Tratamiento informativo de la inmigración (Practical Guide for Media Professionals. Immigration Information Treatment). Madrid, Spain: OBERAXE. Retrieved from http://www.mitramiss.gob.es/ oberaxe/es/publicaciones/documentos/documento_0066.htm

Siham, E. (2018, April 24). Racismo científico: Determinismo biológico y darwinismo social (Scientific Racism: Biological Determinism and Social Darwinism). Esracismo. Retrieved from http://esracismo.com/2018/04/24/racismo-cientifico-determinismo-biologico-ydarwinismo-social/

Tajfel, H. (1971). Social Identity and Intergroup Relations. U.S.A.: Cambridge University Press.

Templeton, A. R. (2013). Biological Races in Humans. Studies in history and philosophy of biological and biomedical sciences, 44(3), 262-271. https://doi.org/10.1016/j.shpsc.2013.04.010

Torres, M. (2011, April 16). Asha Miró: “He tocado el cielo muchísimas veces” (Asha Miró: “I Have touched the sky many times"). Diario de Ibiza. Retrieved from https://www.diariodeibiza.es/ pitiuses-balears/2011/04/16/asha-miro-he-tocado-cielo-veces/476165.html

Turner, J. C., Brown, R. J., \& Tajfel, H. (1979). Social comparison and group interest in group favouritism. European Journal of Social Psychology, 9(2), 187-204. https://doi.org/10.1002/ejsp.2420090207

UNESCO. (1950). La cuestión racial (The racial question). UNESCO Biblioteca digital. Publication no 790. Retrieved from https://unesdoc.unesco.org/ark:/48223/pf0000128289?posInSet $=2 \& q u e r y I d=29 a 237 c 3-5283-421 c-b 853-85413 f 9 b 4 d a 1$

Van Dijk, T. A. (1993). Elite discourse and racism. Newbury Park, CA: Sage Publications.

Van Dijk, T. A. (1997). Racismo y análisis crítico de los medios (Racism and critical media analysis). Barcelona, Spain: Paidós.

Wilson, C., Gutiérrez F., \& Chao, L. M. (2003). Racism, sexism and the media. California, CA: Sage.

\section{SOBRE EL AUTOR}

NICOLÁS LORITE GARCÍA, doctor en Ciencias de la Información y profesor titular del Departamento de Publicidad, Relaciones Públicas y Comunicación Audiovisual de la Universidad Autónoma de Barcelona. Director del MIGRACOM (Observatorio y Grupo de Investigación de Migración y Comunicación) de la UAB desde 1995. Se ha especializado en investigación audiovisual aplicada e investigación-acción, y ha dirigido diferentes investigaciones nacionales e internacionales sobre el estudio multimodal de la representación de las migraciones y la diversidad sociocultural en los medios de comunicación.

(iD) https://orcid.org/0000-0002-6858-5522 